\title{
Density functional approximations for consistent spin and oxidation states of oxoiron complexes
}

\author{
Filip Z. Vlahovic ${ }^{\mathrm{a}}$, Maja Gruden ${ }^{\mathrm{b}}$, Stepan Stepanovic ${ }^{\mathrm{c}}$ and Marcel Swart $\mathrm{d}^{\mathrm{d}, \mathrm{e}}$ \\ a) Innovation center of the Faculty of Chemistry, University of Belgrade, Studentski trg 12-16, 11000 Belgrade, Serbia. \\ b) Faculty of Chemistry, University of Belgrade, Studentski trg 12-16, 11000 Belgrade, Serbia \\ c) Department of Chemistry, IChTM, University of Belgrade, Studentski Trg 12-16, 11001 Belgrade, Serbia \\ d) Institut de Química Computacional i Catàlisi and Departament de Química, Universitat de Girona, Campus Montilivi, Fa- \\ cultat de Ciències, 17003 Girona, Spain \\ e) ICREA, Pg. Lluís Companys 23, 08010 Barcelona, Spain. E-mail: marcel.swart@gmail.com; Fax: +34 972 418150; Tel: \\ +34 972418861
}

KEYWORDS Spin State Energy, Density Functional Approximations, Inorganic Chemistry, High-Valent Metal Complexes

\begin{abstract}
We report here a computational study on a series of $\mathrm{Fe}^{\mathrm{II}}, \mathrm{Fe}^{\mathrm{III}}$ and $\mathrm{Fe}^{\mathrm{IV}}$ hydroxo/oxo-iron complexes with a broad palette of ligands. We are interested in assessing the robustness of widely used density functionals for their prediction and description of structures and spin states for the examined oxoiron complexes. We have used a variety of density functional approximations (S12g, LDA, BP86-D 3 , OPBE, SSB-D, B3LYP-D, S12h and MVS), in all cases including solvation and relativistic effects explicitly. One of the main observations of this detailed study is the excellent performance of S12g for both accurate structures and spin state splittings. Moreover, our results show that in general all density functionals can be used as a reliable computational tool for reproducing and predicting geometries, determining the oxidation state of iron, and most are able as well to providing good descriptions of spin state energetics.
\end{abstract}

\section{INTRODUCTION}

With many significant developments in electronic structure theory and computer science, as well as rapid increases in available computer power, computational modeling has reached a level of maturity where it can provide reliable predictions and, in fact, sometimes may rival experiment in accuracy. In modern chemistry, computer modeling is a prominent means to reduce the cost associated with synthesis, testing, application, and can serve as a tool to explain experimental data in more detail. Furthermore, the combination of accurate structure prediction ${ }^{1}$ and reliable computational spectroscopy ${ }^{2-3}$ makes that computational chemistry is nowadays one of the major techniques used for characterization of chemical species. ${ }^{4-6}$

One of the major research areas that has recently seen a surge in the number of valuable computational studies is inorganic chemistry, in particular those where different oxidation and spin states of (first-row) transition metal (TM) ions are involved. Molecules containing TM ions in their structure have achieved great scientific attention due to their versatile applications in medicine, biology, industry, and catalysis. ${ }^{7-8}$ Out of the plethora of quantum-chemistry techniques, Density Functional Theory (DFT) $)^{9-10}$ has risen to become the main computational tool for investigating, understanding and interpreting various molecular properties. ${ }^{11}$ DFT is based on electronic density ingredients and therefore is able to accurately describe dramatic changes in the properties of the chemical compounds, induced by small changes in the TM coordination sphere or its spin state. ${ }^{12-13}$ For a complete understanding of these compounds one must not only consider the spin ground state, but also the low-lying excited (spin) states. Changes in the orbital occupation patterns (and hence spin states) have potentially a big effect on catalysis $^{14-18}$ but also can lead to changes in the reaction paths that are being followed. ${ }^{19}$ Unfortunately, the resulting intermediates and transition states are in most cases too short-lived for experimental characterization, leading to discussions about their existence and character. This has led directly to the application of computational chemistry, ${ }^{20}$ which is a challenging task because, as every other technique, DFT has its boundaries and limitations.

Whereas DFT is by definition an exact theory and gives the exact energy, ${ }^{21-23}$ the 'universal functional' is unknown and 
probably unattainable. ${ }^{24}$ Instead, in practice all computational chemistry is carried out through the use of density functional approximations (DFAs), of different complexity. ${ }^{25-26}$ By benchmarking against either experimental or high-level theoretical data, the shortcomings and successes of DFAs have been observed, ${ }^{27-28}$ for some more than others, depending on the molecular properties used in the benchmarks tests. ${ }^{29-34}$ Nevertheless, spin state splittings were in general not included in the development of most DFAs, except arguably in the case of B3LYP*35 and indirectly ${ }^{36}$ for the SSB-D ${ }^{37}$ and $\mathrm{S} 12 \mathrm{~g}^{30}$ functionals. The indirect inclusion of spin states in the design of these latter functionals followed the remarkable connection between spin state energies for transition-metal complexes, and barriers for bimolecular substitution $\left(\mathrm{S}_{\mathrm{N}} 2\right)$ reactions. ${ }^{12,36}$

Among the many systems containing TMs, high-valent oxoiron molecules are in particular widely studied, ${ }^{38}$ due to the fact that they play an essential role in the mechanism of heme and nonheme iron enzymes, which play a vital role in our bodies. ${ }^{39-40}$ Various oxoiron complexes have been examined, however questions remain about their structure, oxidation state and spin state, and the effect these have on their properties and reactivity. ${ }^{41-42}$ Many of these uncertainties have been clarified through the use of DFAs, where a direct match between spectroscopic features, spin states and structures could be made. ${ }^{6,20,43-47}$ One widely discussed example is posed by a fascinating $\mathrm{Sc}^{3+}$-capped oxoiron complex $\left[(\mathrm{TMC})\left(\mathrm{Fe}^{\mathrm{III} / \mathrm{IV}}-\mathrm{O}-\mathrm{Sc}^{\mathrm{III}}\right)(\mathrm{OTf})_{4}\left(\mathrm{OH}_{\mathrm{x}}\right)\right](\mathrm{TMC}=$ 1,4,8,11-tetramethyl-1,4,8,11-tetraazacyclotetradecane), synthetized by Fukuzumi, Nam and co-workers and characterized by X-ray crystallography. ${ }^{48}$ However, experimentally obtained bond lengths led to doubts about the assignment of the oxidation state of iron. ${ }^{4142}$ Therefore, one of us performed DFA calculations and concluded that the complex should be reformulated as $\left[(\mathrm{TMC})\left(\mathrm{Fe}^{\mathrm{III}}-\mathrm{O}-\mathrm{Sc}^{\mathrm{III}}\right)(\mathrm{OTf})_{4}\left(\mathrm{OH}_{2}\right)\right]$, with an iron(III) oxidation state in the high-spin configuration. ${ }^{20}$ This shed new light on the scandium-capped complex, with theoretical predictions confirmed experimentally in 2015 by Prakash et al. ${ }^{49}$, who were able to carry out characterization by X-ray, Mössbauer and EPR spectroscopy and unambiguously confirmed the high spin iron(III) state. However, irrespective of the reassignment of the oxidation state, the seminal work by Fukuzumi and $\mathrm{Nam}^{48}$ opened up a complete new approach for the stabilization of volatile species by complexation with a Lewis acid, ${ }^{50-55}$ and has brought forward new insights into the electronic structure of these short-lived species.

In the present work, the ability of various DFAs to reproduce experimental data has been verified for a total of 14 oxoiron complexes (see Figure 1 and Table S1), with the aim to find the best choice of DFA (if any) for optimizing geometries and studying the diversity of spin state preferences. One of us showed ${ }^{20}$ in 2013 that accurate structural parameters could be obtained for a set of iron(III/IV) complexes at the PBE-D $/$ TZ2P, whereas here we expand this set with recently characterized complexes to perform a thorough study of starting geometry influence and choice of DFA on obtained results. The examined set of iron molecules includes $\mathrm{Fe}^{\mathrm{II}}$-hydroxo, $\mathrm{Fe}^{\mathrm{III}}$-oxo, $\mathrm{Fe}^{\mathrm{III}}$-hydroxo, and $\mathrm{Fe}^{\mathrm{III}}$-peroxo complexes, as well as $\mathrm{Fe}^{\mathrm{IV}}$-oxo complexes, together with the challenging $\mathrm{Sc}^{3+}$-capped complexes (vide supra). Furthermore, we have studied the thermodynamics for the process of formation of the scandium triflate adduct with the $\mathrm{Fe}^{\mathrm{IV}}$-oxo complex, ${ }^{42,48}$ which gives detailed insight into its formation and confirmation of the oxidation state of iron in this $\mathrm{Sc}^{3+}$-capped complex.

\section{COMPUTATIONAL DETAILS}

All DFA calculations were performed with the Amsterdam Density Functional (ADF) ${ }^{56-57}$ and QUILD ${ }^{58}$ program, except Hartree Fock (HF) single point calculations that were carried out with the Gaussian $09^{59}$ program. Molecular orbitals were expanded in ADF in an uncontracted set of Slater type orbitals (STOs) of triple- $\zeta$ quality with double polarization functions (TZ2P), or the TDZP basis set which consists of triple- $\zeta$ quality on the metal and double- $\zeta$ quality on all other atoms, in both cases including one polarization function. ${ }^{60-61}$ Core electrons were not treated explicitly during geometry optimizations (frozen core approximation). An auxiliary set of s, p, d, f, and $g$ STOs was used to fit the molecular density and to represent the Coulomb and exchange potentials accurately for each SCF cycle.

Geometries of all possible spin states were optimized with the QUILD $^{58}$ program using adapted delocalized coordinates ${ }^{62}$ until the maximum gradient component was less than $10^{-4}$ a.u. Energies and gradients were calculated using $\mathrm{LDA}^{63}, \mathrm{PBE}_{-} \mathrm{D}_{2}{ }^{32}$, $\mathrm{S} 12 \mathrm{~g}^{30}, \mathrm{BP} 86-\mathrm{D}_{3}{ }^{64-65}, \mathrm{~B} 3 \mathrm{LYP}-\mathrm{D}_{3}{ }^{66}$ and $\mathrm{S} 12 \mathrm{~h}^{30}$ functionals, in all cases by including solvation effects through the $\mathrm{COSMO}^{67-68}$ dielectric continuum model with appropriate parameters for each solvent used. Scalar relativistic corrections have been included self-consistently in all calculations by using the zerothorder regular approximation (ZORA) ${ }^{69-70}$. Geometry optimizations at the BP86- $\mathrm{D}_{3}$ level of theory were performed with TDZP (providing a rapid route towards the structures of the complexes) and TZ2P basis sets, and optimizations with LDA (Slater exchange ${ }^{71-72}$ with Vosko-Wilk-Nusair ${ }^{63}$ correlation), PBE-D $_{2}, \mathrm{~S} 12 \mathrm{~g}, \mathrm{~B} 3 \mathrm{LYP}_{3}, \mathrm{D} 12 \mathrm{~h}$ were performed with the TZ2P basis set. Subsequent single-point calculations (with the all-electron TZ2P basis set) have been performed on all optimized geometries, with $\mathrm{S} 12 \mathrm{~g}, \mathrm{BP} 86-\mathrm{D}_{3}, \mathrm{OPBE}^{73}, \mathrm{SSB}-\mathrm{D}^{37}$, B3LYP-D 3 , S12h, and $\mathrm{MVS}^{29}$. For all calculations carried out with LDA, PBE-D 2 , OPBE, BP86-D 3 , and B3LYP-D ${ }_{3}$ the Becke $^{74-75}$ grid of normal quality was used; calculations performed with SSB-D, S12g and S12h were performed with a Becke grid of very good quality, and for MVS a grid of good quality with five times radial-grid boost was applied. Note that BP86- ${ }_{3}, \mathrm{~S} 12 \mathrm{~g}, \mathrm{~B} 3 \mathrm{LYP}-\mathrm{D}_{3}$ and $\mathrm{S} 12 \mathrm{~h}$ include Grimme's $\mathrm{D}_{3}{ }^{76}$ while $P B E-D_{2}$ and SSB-D functional include Grimme's $\mathrm{D}_{2}$ dispersion energy scheme, ${ }^{32}$ in all cases with appropriate parameters for each functional separately. MVS was shown to already include a large part of the dispersion interactions implicitly for short- and medium-range weak interactions, ${ }^{29}$ and hence there 
is less need to combine MVS with Grimme's $\mathrm{D}_{3}$ scheme (although efforts to also describe long-range interactions correctly may be forthcoming). All DFA calculations were performed using the unrestricted Kohn-Sham scheme.

Unrestricted HF single point calculations of previously optimized structures were carried out with the $6-311+\mathrm{G}(\mathrm{d}, \mathrm{p})^{77-79}$ basis set. These calculations were carried out using the Gaussian program because the HF method does not necessarily need a numerical grid, and hence can be used more conveniently with a GTO-based program. In both programs however, there are severe problems in getting the SCF equations to converge for Hartree-Fock, especially for the non-ground state spin-states. These problems, combined with the necessity of some technical combination of keywords made accurate HF calculations of some complicated transition metal systems a formidable task, highlighting again the limited usability of the method for transitionmetal chemistry. For that reason, no HF results will be shown here.

\section{RESULTS AND DISCUSION}

First, we have examined the performance of a range of DFAs for geometry optimizations for a series of well characterized $\mathrm{Fe}^{\mathrm{II}} / \mathrm{Fe}^{\mathrm{III}} / \mathrm{Fe}^{\mathrm{IV}}$ hydroxo/peroxo/oxoiron complexes with a broad palette of ligands. Structural and spectroscopic characterization of all calculated complexes can be found in the original papers, with a summary of the relevant data and literature/CCDC references being given in the Supporting Information. ${ }^{80-103}$ It should be noted that compared to the previous study, here we only take complexes into account for which X-ray data are available, in order to avoid possible uncertainties about the conformations of the ligands.

In order to find the best agreement with these X-ray structures, we have used three classes of DFAs: (i) the local density approximation (LDA); (ii) three general gradient approximation (GGA) functionals, S12g, BP86-D ${ }_{3}$, and PBE-D 2 ; and (iii) two hybrid functional, B3LYP-D $\mathrm{D}_{3}$ and $\mathrm{S} 12 \mathrm{~h}$. The optimized structures are overall consistent and in good agreement with the previously reported set of complexes ${ }^{20}$ and with experimental data (Figure 2). It should be noted that in ref. 20 two outliers were reported, $\left[\mathrm{Fe}^{\mathrm{III}}(\mathrm{OH})\left(\mathrm{H}_{3} \text { buea }\right)\right]^{-}$and $\left[\mathrm{Fe}^{\mathrm{III}}(\mathrm{OOH})\left(\mathrm{TMC}^{\mathrm{i}}\right)\right]^{2+}$, that showed apparent deviations of ca. 0.08-0.10 ̊. However, upon reinvestigating the original sources ${ }^{81,84}$, it was found that the experimental data mentioned ${ }^{20}$ were referring to complexes with iron in a different oxidation state; the actual experimental $\mathrm{Fe}-\mathrm{O}$ distances for $\left[\mathrm{Fe}^{\mathrm{III}}(\mathrm{OH})\left(\mathrm{H}_{3} \text { buea }\right)\right]^{-}(1.93 \AA)^{82}$ and $\left[\mathrm{Fe}^{\mathrm{III}}(\mathrm{OOH})\left(\mathrm{TMC}^{\mathrm{i}}\right)\right]^{2+}(1.85 \AA)^{85}$ are in fact in excellent agreement with the computed data of $1.932 \AA$ and $1.842 \AA$, respectively. Here we use the corrected data for $\left[\mathrm{Fe}^{\mathrm{III}}(\mathrm{OH})\left(\mathrm{H}_{3}\right.\right.$ buea $\left.)\right]$ (see Tables S1-S2).
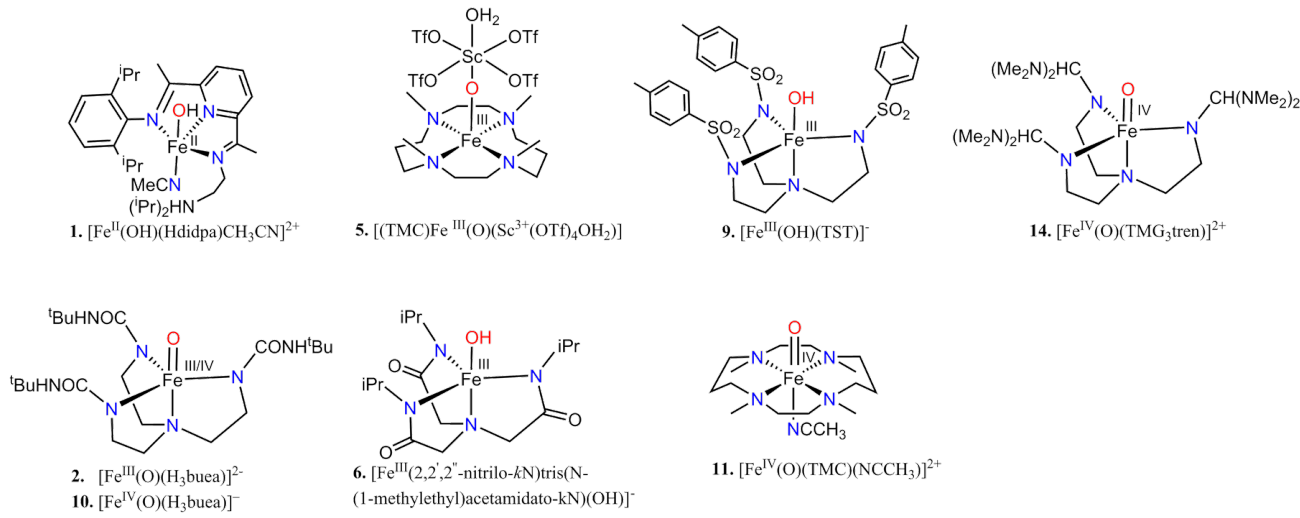

11. $\left[\mathrm{Fe}^{\mathrm{IV}}(\mathrm{O})(\mathrm{TMC})\left(\mathrm{NCCH}_{3}\right)\right]^{2+}$
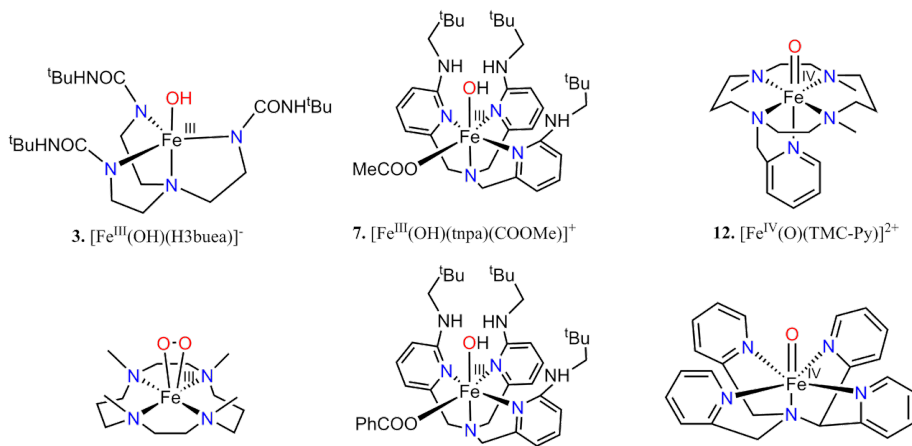

4. $\left[\mathrm{Fe}^{\mathrm{III}}(\mathrm{OO})(\mathrm{TMC})\right]$
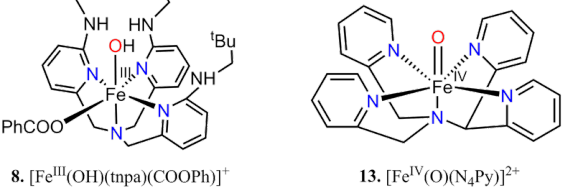

13. $\left[\mathrm{Fe}^{\mathrm{IV}}(\mathrm{O})\left(\mathrm{N}_{4} \mathrm{Py}\right)\right]^{2+}$

Figure 1. Structures of all investigated $\mathrm{Fe}^{\mathrm{II}} / \mathrm{Fe}^{\mathrm{III}} / \mathrm{Fe}^{\mathrm{IV}}$ hydroxo/peroxo/oxoiron complexes 
First of all, we focus on the optimized geometries of the experimentally observed spin ground state for each of the fourteen complexes for which crystallographic data are available to compare with. Bond lengths of interest for our work are in all cases the axial iron-oxygen ( $\mathrm{Fe}-\mathrm{O})$ distance (related to oxo, hydroxo, peroxo), the axial iron-nitrogen $\left(\mathrm{Fe}-\mathrm{N}_{a x}\right)$ distance and the average of the in-plane iron-nitrogen/oxygen (Fe$\mathrm{N} / \mathrm{O}_{e q}$ ) distances. The best agreement with experimentally observed axial $\mathrm{Fe}-\mathrm{O}$ bond lengths was obtained using the disper-

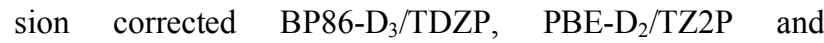
S12g/TZ2P, with a mean absolute deviation of 0.011-0.014 $\AA$ (see Figure 2 and Table S2). If we take a look at the in-plane (equatorial) $\mathrm{Fe}-\mathrm{N}_{e q} / \mathrm{Fe}-\mathrm{O}_{e q}$ bond lengths, we found that BP86$\mathrm{D}_{3}$ and PBE- $\mathrm{D}_{2}$ DFAs gave the best results, and provided excellent agreement with experiment, with a mean absolute error value of 0.013 and $0.014 \AA$ respectively for $\mathrm{Fe}-\mathrm{N}_{\mathrm{eq}}$ (Table S3), and 0.004 and $0.006 \AA$ for $\mathrm{Fe}-\mathrm{O}_{\text {eq }}$. The axial $\mathrm{Fe}-\mathrm{N}_{a x}$ bonds show in all cases larger differences between DFT and experiment (0.04-0.07 $\AA$ ), which might indicate either that crystal packing effects have a larger influence on the axial bonds than on the equatorial ones, or there is a general problem with DFAs for describing these axial nitrogen bonds; we will return to this question in future studies. Overall, if we take into account all iron-ligand bond lengths, the DFA showing the best overall performance for these mono-nuclear complexes is BP86- $\mathrm{D}_{3}$, in particular with the TDZP basis, which is therefore a fast route to accurate transition-metal complexes. It should be added that in a separate study on an anti-ferromagnetically coupled high-spin diiron complex one of us observed that the good performance of BP86- $\mathrm{D}_{3}$ is lost there because of its inability to properly describe spin states (vide infra). Given the good performance of S12g/TZ2P for both mono-nuclear and di-nuclear complexes, a more generally applicable route to accurate transition-metal complexes is therefore obtained at the S12g/TZ2P level.

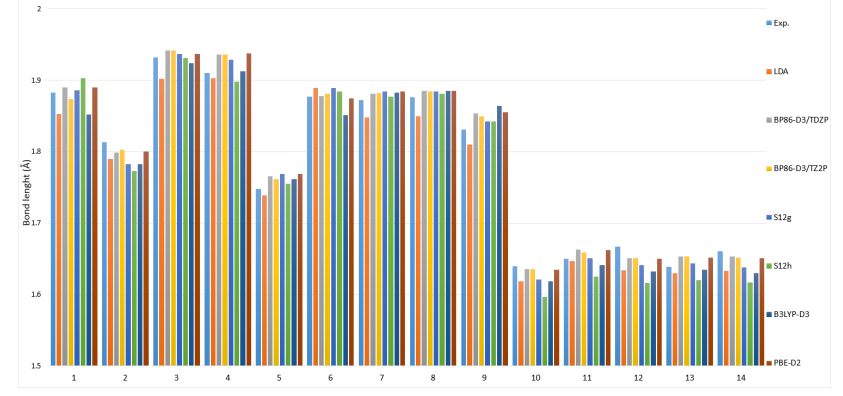

Figure 2. The difference between the experimentally obtained $\mathrm{Fe}^{\mathrm{II} /} / \mathrm{Fe}^{\mathrm{III}} / \mathrm{Fe}^{\mathrm{IV}}$-oxygen distances and those from DFAs for all oxoiron species listed in Table S1 and Figure 1.

Next step in our research was to find an accurate way to unambiguously determine the correct spin ground state. All complexes under investigation contain iron as the central metal ion with partially filled d-shells, thus one has to consider more than one possible spin state, which are in many cases close in energy. 11 structures optimized on different levels of theory were further investigated, calculating the relative spin state energy, in order to find the best DFA for precise determination and description of the spin ground state. Relative spin state energetics were calculated in a single point fashion using two standard (LDA, BP86- $\mathrm{D}_{3}$ ), two hybrid (B3LYP-D ${ }_{3}$ and $\mathrm{S} 12 \mathrm{~h}$ ), and three functionals specially designed for this particular kind of problem (OPBE, SSBD and $\mathrm{S} 12 \mathrm{~g}$ ). In this study we also present the results obtained with the new meta-GGA 'made very simple' functional (MVS ${ }^{29}$, designed by Perdew and co-workers. Considering the fact that the geometry and metal-ligand distances are important for distinguishing of the different spin ground states,$^{13}$ we present here spin state energetics calculated with different DFAs mentioned before on $\mathrm{BP} 86-\mathrm{D}_{3}$ optimized geometries (Figure 3); these DFA structures were the closest to the crystallographic data (vide supra). Data for all DFA-optimized structures and with a total of eight DFA single-point energy calculations is included in the supplementary material (Table T1-T14).
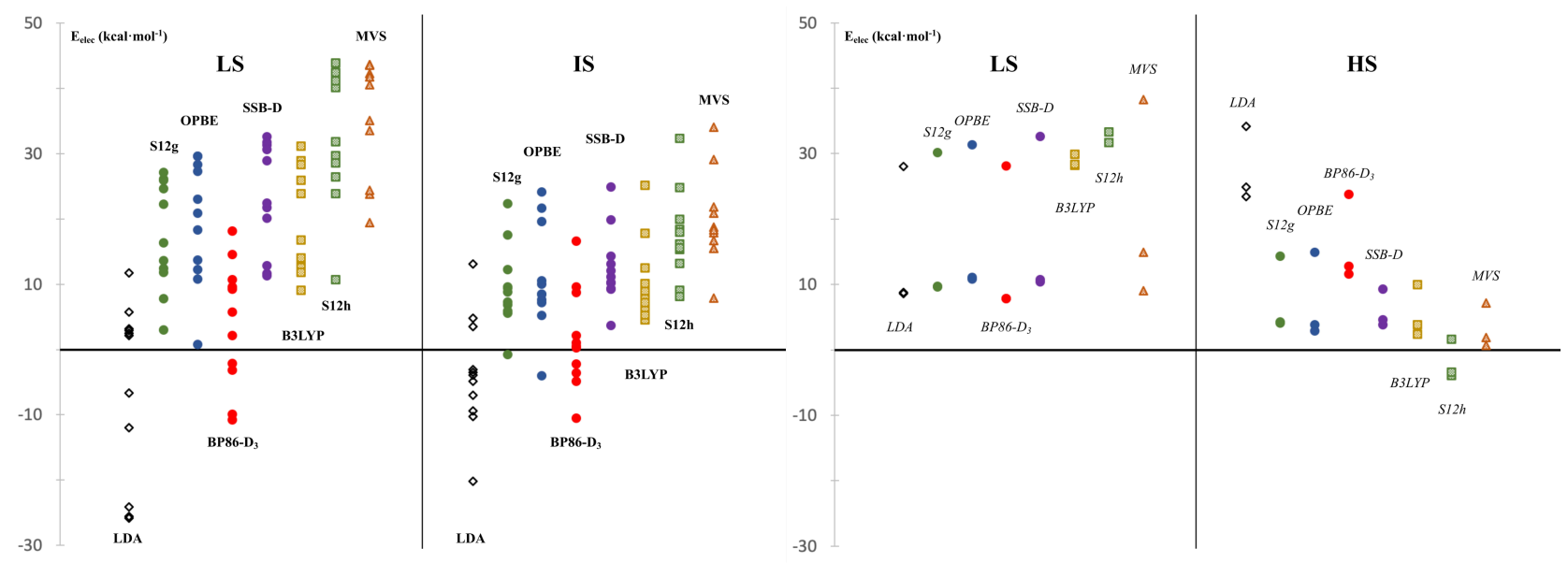

Figure 3. Spin-state splittings $\left(\mathrm{kcal} \cdot \mathrm{mol}^{-1}\right)$ for the fourteen complexes as obtained in single-point energy calculations with eight DFAs on BP86-D/TDZP structures: (left) results for complexes 1-10, 14 (HS); (right) results for complexes 11-13 (IS). 
The experimentally determined spin ground state of the $\mathrm{Fe}^{\mathrm{II}}$, $\mathrm{Fe}^{\mathrm{III}}$ and $\mathrm{Fe}^{\mathrm{IV}}$ species studied here is either intermediate (IS, 11-13) or high-spin (HS, 1-10 and 14). The systematic overestimation of high-spin by Hartree-Fock, and the effect this has on hybrid functionals is well documented: they favor high spin states and suffer from spin contamination. ${ }^{104}$ Here, however, the effect is not so dramatic. Hybrid S12h (with 25\% HF exchange included) indeed favors a high spin state for 11/12 (by $-3.9 \mathrm{kcal} \cdot \mathrm{mol}^{-1}$ ), but gives the correct IS state for 13 . On the other hand, B3LYP-D 3 (20\% HF exchange) showed the correct spin state for of these IS complexes. For the high-spin complexes, LDA and BP86- $\mathrm{D}_{3}$ fail to predict properly the HS ground state, which has been described extensively in the literature. The best performance for the correct description of spin ground state is obtained with OPBE, S12g and SSB-D. These three DFAs are especially designed to deal with this delicate and demanding task, and they showed success in many similar works from the past. ${ }^{45}, 73,105-108$ Spin ground states determined with OPBE, S12g and SSB-D are in accordance with the experiment for all examined iron-oxo complexes, except for the $\left[\mathrm{Fe}^{\mathrm{II}}(\mathrm{OH})(\mathrm{Hdidpa})\left(\mathrm{CH}_{3} \mathrm{CN}\right)\right]^{2+}(\mathbf{1})$ complex. However, this result is obtained by looking only at the electronic energy; if we actually focus on the Gibbs free energy, the $\Delta \Delta \mathrm{G}$ correction is $4.06 \mathrm{kcal} \cdot \mathrm{mol}^{-1}$ in favor of the high-spin. This makes the high-spin state favored by OPBE only slightly $\left(0.1 \mathrm{kcal} \cdot \mathrm{mol}^{-1}\right)$, but significantly by S12g (3.3 $\mathrm{kcal} \cdot \mathrm{mol}^{-1}$ ). As a result, $\mathrm{S} 12 \mathrm{~g}$ correctly predicts a high-spin state for complex $\mathbf{1}$, which is another confirmation of the good performance of $\mathrm{S} 12 \mathrm{~g}$ shown in the past. Therefore, one of the main conclusions of our work is that a reliable way for accurate prediction of the spin ground state is to employ dispersion corrected S12g simultaneously for both geometry optimization and relative spin state energy calculation; they may be sped up for mono-nuclear complexes by using BP86$\mathrm{D}_{3} /$ TDZP geometries.

Now we can return to one of the challenges posed by the scandium-capped iron-oxygen complex. One of us already showed in 2013 that the oxidation state of iron changes to Fe(III), which was confirmed subsequently by spectroscopy, and followed up by a study using chromium. ${ }^{109}$ However, one aspect of the capping process was not yet explored: how strongly bound is the $\left[\mathrm{Sc}(\mathrm{OTf})_{4}\left(\mathrm{OH}_{2}\right)\right]^{-}$moiety? After the preceding parts on geometries and spin-state energies, we are now in a position to be able to shed light on this with confidence that the structures and energies will be well described. Therefore, we studied the $\left[\mathrm{Fe}^{\mathrm{n}}(\mathrm{O})\left(\mathrm{Sc}(\mathrm{OTf})_{4}\left(\mathrm{OH}_{\mathrm{m}}\right)\right]\right.$ complexes with $\mathrm{S} 12 \mathrm{~g} / \mathrm{TZ2P}$ energies on BP86-D 3 /TDZP structures. Here we focus only on the reaction thermochemistry, and not on kinetics. The computed thermochemical properties of different reactions involved in the creation of the scandium-capped ironoxygen complex are shown in the supporting information. Here we show the summary (Figure 4 ) of the overall process.

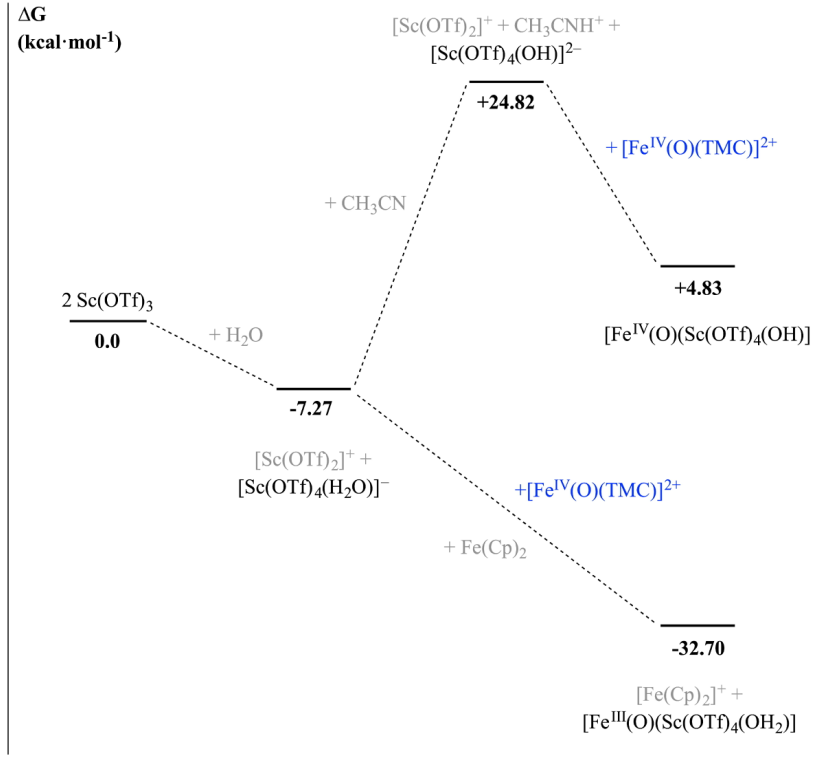

Figure 4. Formation of the scandium-capped iron-oxygen complex $\left[\mathrm{Fe}^{\mathrm{III}}(\mathrm{O}) \mathrm{Sc}(\mathrm{OTf})_{4}\left(\mathrm{OH}_{2}\right)\right]$.

The capping of the $\left[\mathrm{Fe}^{\mathrm{IV}}(\mathrm{O})(\mathrm{TMC})\right]^{2+}$ by scandium is thus shown to be exergonic in case of forming the Fe(III) complex; the formation of a putative scandium-capped Fe(IV)-oxygen complex is however found to be endergonic. These findings are fully consistent with the $\mathrm{Fe}-\mathrm{O}$ and $\mathrm{Sc}-\mathrm{O}$ distances found in the crystal structure, ${ }^{48}$ and the DFT study, ${ }^{20}$ and the Mössbauer studies (both the computational prediction ${ }^{20}$ and experimental corroboration ${ }^{49}$ ).

\section{CONCLUSION}

Within this study the extension of the previous validation ${ }^{20}$ of various DFAs for correct description of spin state energetics for a series of $\mathrm{Fe}^{\mathrm{II}} / \mathrm{Fe}^{\mathrm{III}} / \mathrm{Fe}^{\mathrm{IV}}$ oxo-iron complexes is presented. Bearing in mind that changing of the spin-state is often associated with changing of the geometry, structure relaxation of the LS, IS and HS state of 14 oxo-iron species was allowed with eight density functionals. Our theoretical findings, in accordance with experimental data, suggest that the HS or IS configuration is favored for all investigated species by the means of DFAs using OPBE, SSB-D, S12g, MVS and B3LYP-D ${ }_{3}$. However, LDA, BP86- $\mathrm{D}_{3}$ and $\mathrm{S} 12 \mathrm{~h}$ showed a tendency to predict wrong spin ground state on the BP86- $\mathrm{D}_{3}$ optimized geometries. Overall geometries, obtained at $\mathrm{S} 12 \mathrm{~g} / \mathrm{TZ2P}$ and BP86-D $/$ TDZP level of theories (including COSMO solvation and ZORA relativistic corrections) are in excellent agreement with the experimental data, for all molecules under study. It is noteworthy that $\mathrm{BP} 86-\mathrm{D}_{3} / \mathrm{TDZP}$ gave the best agreement with experimentally observed $\mathrm{Fe}-\mathrm{O}$ and $\mathrm{Fe}-\mathrm{N}_{\mathrm{eq}}$ distances, while results for $\mathrm{Fe}-\mathrm{N}_{\mathrm{ax}}$ are satisfactory. When considered together, obtained data support few important conclusions: although one should be cautious while choosing the DFA for a correct prediction of spin ground state, accurate spin state energies can be easily derived performing fast and efficient high level theory single point 
calculations on correct geometry (for mononuclear metal complexes!). For all complexes under investigation the best performance in determination of the spin ground state was obtained with OPBE, S12g and SSB-D, what makes them an important tool for exploring and describing different spine states of various transition metal containing systems.

With the caution that different research groups would recommend the use of different functionals, encouraged with these results we suggest $\mathrm{S} 12 \mathrm{~g} / \mathrm{TZ} 2 \mathrm{P}$ as the most reliable choice for both geometry optimization and spin state splittings in transition-metal complexes: it provides both good geometries, and an accurate description of the electronic structure. This comprehensive validation study give us confidence to use $\mathrm{S} 12 \mathrm{~g}$ for studying and predicting properties of unknown transitionmetal compounds, which ultimately is one of the aims of theoretical (bio)inorganic chemistry.

After many discussions in the past $\mathrm{t}^{20,48-49}$ about oxidation and spin state of iron in scandium-capped iron-oxygen complex, here we provide additional computational support for the assignment of a Fe(III) oxidation state. The thermochemically most stable iron complex is unambiguously $\left[\mathrm{Fe}^{\mathrm{III}}(\mathrm{O})\left(\mathrm{Sc}(\mathrm{OTf})_{4}\left(\mathrm{H}_{2} \mathrm{O}\right)\right]\right.$, with a high spin ground state.

\section{ASSOCIATED CONTENT}

The Supporting Information is available free of charge on the ACS Publications website at DOI: XXX Contents: Tables with geometrical data for 14 investigated hydroxo/oxo-iron complexes (Tables S1-S5), obtained with different density functionals (Tables T1-T14), summary of experimental data for crystallographic characterization, and coordinates of the species involved in the thermochemistry of scandium-capped iron oxygen complex.

\section{AUTHOR INFORMATION}

\section{Corresponding Author}

* E-mail: marcel.swart@gmail.com

\section{ACKNOWLEDGMENT}

The following organizations are thanked for financial support: the Ministerio de Economia y Competitividad (MINECO, projects CTQ2014-59212-P, CTQ2015-70851-ERC, and CTQ201787392-P), the DIUE of the Generalitat de Catalunya (project 2014SGR1202, and Xarxa de Referència en Química Teòrica i Computacional), the European Fund for Regional Development (FEDER, UNGI10-4E-801), and the Serbian Ministry of Education and Science (Grant No. 172035). This work was performed in the framework of the COST action CM1305 "Explicit Control Over Spin-states in Technology and Biochemistry (ECOSTBio)', resulting from a Short-Term Scientific Mission (COST-STSMCM1305-34080).

\section{REFERENCES}

1. Swart, M.; Snijders, J. G., Accuracy of geometries: influence of basis set, exchange-correlation potential, inclusion of core electrons, and relativistic corrections. Theor. Chem. Acc. 2003, $110(1), 34-41$.

2. Rokob, T. A.; Srnec, M.; Rulisek, L., Theoretical calculations of physico-chemical and spectroscopic properties of bioinorganic systems: current limits and perspectives. Dalton Trans. 2012, 41 (19), 5754-5768.

3. Gruden, M.; Browne, W. R.; Swart, M.; Duboc, C., Computational vs. experimental spectroscopy for transition-metals. In Transition metals in coordination environments: computational chemistry and catalysis viewpoints, E. Broclawik, T. B., M. Radon, Ed. Springer, Cham: 2019; pp 161-183.

4. Engelmann, X.; Malik, D. D.; Corona, T.; Warm, K.; Farquhar, E. R.; Swart, M.; Nam, W.; Ray, K., Trapping of a Highly Reactive Oxoiron(IV) Complex in the Catalytic Epoxidation of Olefins by Hydrogen Peroxide. Angewandte Chemie-International Edition 2019, 58, 4012-4016.

5. Rajabimoghadam, K.; Darwish, Y.; Bashir, U.; Pitman, D.; Eichel-berger, S.; Siegler, M. A.; Swart, M.; Garcia-Bosch, I., Catalytic Aerobic Oxidation of Alcohols by Copper Complexes Bearing Redox-Active Ligands with Tunable H-bonding Groups. Journal of the American Chemical Society 2018, submitted.

6. Padamati, S. K.; Angelone, D.; Draksharapu, A.; Primi, G.; Martin, D. J.; Tromp, M.; Swart, M.; Browne, W. R., Transient Formation and Reactivity of a High-Valent Nickel(IV) Oxido Complex. J. Am. Chem. Soc. 2017, 139 (25), 8718-8724.

7. Ray, K.; Pfaff, F. F.; Wang, B.; Nam, W., Status of Reactive Non-Heme Metal-Oxygen Intermediates in Chemical and Enzymatic Reactions. J. Am. Chem. Soc. 2014, 136 (40), 1394213958.

8. Swart, M.; Costas, M., Spin States in Biochemistry and Inorganic Chemistry: Influence on Structure and Reactivity. Wiley: 2015.

9. Koch, W.; Holthausen, M. C., A Chemist's Guide to Density Functional Theory. Wiley-VCH Verlag GmbH: Weinheim, 2001.

10. Parr, R. G.; Yang, W., Density-functional theory of atoms and molecules. Oxford University Press: New York, Oxford, 1994; 352.

11. Cramer, C. J.; Truhlar, D. G., Density functional theory for transition metals and transition metal chemistry. Phys. Chem. Chem. Phys. 2009, 11 (46), 10757-10816.

12. Swart, M.; Gruden, M., Spinning around in TransitionMetal Chemistry. Acc. Chem. Res. 2016, 49 (12), 2690-2697.

13. Andris, E.; Navrátil, R.; Jasik, J.; Thibault, T.; Srnec, M.; Costas, M.; Roithova, J., Chasing the Evasive $\mathrm{Fe}=\mathrm{O}$ Stretch and the Spin State of the Iron(IV)-Oxo Complexes by Photodissociation Spectroscopy. J. Am. Chem. Soc. 2017, 10.1021/jacs.6b12291.

14. Shaik, S.; Shurki, A., Valence Bond Diagrams and Chemical Reactivity. Angewandte Chemie International Edition 1999, 38 (5), 586-625.

15. Shaik, S., Biomimetic chemistry: Iron opens up to high activity. Nat Chem 2010, 2 (5), 347-349.

16. Kazaryan, A.; Baerends, E. J., Ligand Field Effects and the High Spin-High Reactivity Correlation in the H Abstraction by NonHeme Iron(IV)-Oxo Complexes: A DFT Frontier Orbital Perspective. ACS Catal. 2015, 5 (3), 1475-1488.

17. Zolnhofer, E. M.; Käß, M.; Khusniyarov, M. M.; Heinemann, F. W.; Maron, L.; van Gastel, M.; Bill, E.; Meyer, K., An Intermediate Cobalt(IV) Nitrido Complex and its N-Migratory Insertion Product. J. Am. Chem. Soc. 2014, 136 (42), 15072-15078.

18. Schmidt, A.-C.; Heinemann, F. W.; Maron, L.; Meyer, K., A Series of Uranium (IV, V, VI) Tritylimido Complexes, Their Molecular and Electronic Structures and Reactivity with CO2. Inorg. Chem. 2014, 53 (24), 13142-13153.

19. Johansson, M. P.; Swart, M., Subtle effects control the polymerisation mechanism in [small alpha]-diimine iron catalysts. Dalton Trans. 2011, 40 (33), 8419-8428.

20. Swart, M., A change in the oxidation state of iron: scandium is not innocent. Chem. Commun. 2013, 49 (59), 6650-6652.

21. Kohn, W.; Sham, L. J., Self-Consistent Equations Including Exchange and Correlation Effects. Phys. Rev. 1965, 140 (4A), A1133-A1138.

22. Hohenberg, P.; Kohn, W., Inhomogeneous Electron Gas. Phys. Rev. 1964, 136 (3B), B864-B871. 
23. Cohen, M. H.; Car, R., Dynamical optimization for partition theory. J. Phys. Chem. A 2008, 112 (3), 571-575.

24. Cohen, A. J.; Mori-Sánchez, P.; Yang, W., Insights into Current Limitations of Density Functional Theory. Science 2008, $321,792-794$

25. Mardirossian, N.; Head-Gordon, M., Thirty years of density functional theory in computational chemistry: an overview and extensive assessment of 200 density functionals. Molecular Physics 2017, 115, 2315-2372.

26. Becke, A. D., Perspective: Fifty years of densityfunctional theory in chemical physics. Journal of Chemical Physics 2014, 140, 18A301.

27. Goerigk, L.; Hansen, A.; Bauer, C.; Ehrlich, S.; Najibi, A.; Grimme, S., A look at the density functional theory zoo with the advanced GMTKN55 database for general main group thermochemistry, kinetics and noncovalent interactions. Physical Chemistry Chemical Physics 2017, 19, 32184-32215.

28. Medvedev, M. G.; Bushmarinov, I. S.; Sun, J.; Perdew, J. P.; Lyssenko, K. A., Density functional theory is straying from the path toward the exact functional. Science 2017, 355, 49-52.

29. Sun, J.; Perdew, J. P.; Ruzsinszky, A., Semilocal density functional obeying a strongly tightened bound for exchange. Proceedings of the National Academy of Sciences 2015, 112 (3), 685689.

30. Swart, M., A new family of hybrid density functionals. Chem. Phys. Lett. 2013, 580, 166-171.

31. Conradie, J.; Ghosh, A., Electronic Structure of TrigonalPlanar Transition-Metal-Imido Complexes: Spin-State Energetics, Spin-Density Profiles, and the Remarkable Performance of the OLYP Functional. J. Chem. Theory Comp. 2007, 3 (3), 689-702.

32. Grimme, S., Semiempirical GGA-type density functional constructed with a long-range dispersion correction. J. Comput. Chem. 2006, 27 (15), 1787-1799.

33. Perdew, J. P.; Burke, K.; Ernzerhof, M., Generalized Gradient Approximation Made Simple. Phys. Rev. Lett. 1996, 77 (18), 3865-3868.

34. Becke, A. D., Density-functional thermochemistry. III. The role of exact exchange. The Journal of Chemical Physics 1993, $98(7), 5648-5652$.

35. Reiher, M.; Salomon, O.; Artur Hess, B. Reparameterization of hybrid functionals based on energy differences of states of different multiplicity. Theor. Chem. Acc. 2001, 107 (1), 48-55.

36. Runge, E.; Gross, E. K. U., Density-Functional Theory for Time-Dependent Systems. Phys. Rev. Lett. 1984, 52 (12), 997-1000.

37. Swart, M.; Solà, M.; Bickelhaupt, F. M., A new all-round density functional based on spin states and SN2 barriers. The Journal of Chemical Physics 2009, 131 (9), 094103.

38. Swart, M., Spin states of (bio)inorganic systems: successes and pitfalls. International Journal of Quantum Chemistry 2013, 113 , $2-7$.

39. Yin, G., Active transition metal oxo and hydroxo moieties in nature's redox, enzymes and their synthetic models: Structure and reactivity relationships. Coord. Chem. Rev. 2010, 254 (15-16), 18261842 .

40. Company, A.; Gomez, L.; Costas, M., Chapter 6 Bioinspired Non-heme Iron Catalysts in $\mathrm{C}-\mathrm{H}$ and $\mathrm{C}=\mathrm{C}$ Oxidation Reactions. In Iron-Containing Enzymes: Versatile Catalysts of Hydroxylation Reactions in Nature, The Royal Society of Chemistry: 2011; pp 148-208.

41. McDonald, A. R.; Que Jr, L., High-valent nonheme ironoxo complexes: Synthesis, structure, and spectroscopy. Coord. Chem. Rev. 2013, 257 (2), 414-428.

42. Morimoto, Y.; Kotani, H.; Park, J.; Lee, Y.-M.; Nam, W.; Fukuzumi, S., Metal Ion-Coupled Electron Transfer of a Nonheme Oxoiron(IV) Complex: Remarkable Enhancement of ElectronTransfer Rates by Sc3+. J. Am. Chem. Soc. 2011, 133 (3), 403-405.

43. Vanpoucke, D. E. P.; Bultinck, P.; Cottenier, S.; Van Speybroeck, V.; Van Driessche, I., Aliovalent doping of CeO2: DFT study of oxidation state and vacancy effects. Journal of Materials Chemistry A 2014, 2 (33), 13723-13737.
44. Jacobsen, H.; Kraatz, H. B.; Ziegler, T.; Boorman, P. M. A new look at an old ligand: surprises with thioethers. A density functional study. J. Am. Chem. Soc. 1992, 114 (20), 7851-7860.

45. Gruden-Pavlovic, M.; Stepanovic, S.; Peric, M.; Guell, M.; Swart, M., A density functional study of the spin state energetics of polypyrazolylborato complexes of first-row transition metals. Phys. Chem. Chem. Phys. 2014, 16 (28), 14514-14522.

46. Hill, E. A.; Weitz, A. C.; Onderko, E.; Romero-Rivera, A.; Guo, Y.; Swart, M.; Bominaar, E. L.; Green, M. T.; Hendrich, M. P.; Lacy, D. C.; Borovik, A. S., Reactivity of an FeIV-Oxo Complex with Protons and Oxidants. J. Am. Chem. Soc. 2016, 138 (40), 13143 13146.

47. Pirovano, P.; Farquhar, E. R.; Swart, M.; Fitzpatrick, A. J.; Morgan, G. G.; McDonald, A. R., Characterization and Reactivity of a Terminal Nickel(III)-Oxygen Adduct. Chemistry (Weinheim an der Bergstrasse, Germany) 2015, 21 (9), 3785-3790.

48. Fukuzumi, S.; Morimoto, Y.; Kotani, H.; Naumov, P.; Lee, Y.-M.; Nam, W., Crystal structure of a metal ion-bound oxoiron(IV) complex and implications for biological electron transfer. Nat. Chem. 2010, 2 (9), 756-759.

49. Prakash, J.; Rohde, G. T.; Meier, K. K.; Jasniewski, A. J.; Van Heuvelen, K. M.; Münck, E.; Que, L., Spectroscopic Identification of an FeIII Center, not FeIV, in the Crystalline Sc-OFe Adduct Derived from [FeIV(O)(TMC) $] 2+$. J. Am. Chem. Soc. 2015, 137 (10), 3478-3481.

50. Pfaff, F. F.; Kundu, S.; Risch, M.; Pandian, S.; Heims, F.; Pryjomska-Ray, I.; Haack, P.; Metzinger, R.; Bill, E.; Dau, H.; Comba, P.; Ray, K., An oxocobalt(IV) complex stabilized by Lewis acid interactions with scandium(III) ions. Angewandte ChemieInternational Edition 2011, 50 (7), 1711-5.

51. Kundu, S.; Miceli, E.; Farquhar, E.; Pfaff, F. F.; Kuhlmann, U.; Hildebrandt, P.; Braun, B.; Greco, C.; Ray, K., Lewis Acid trapping of an elusive copper-tosylnitrene intermediate using scandium triflate. Journal of the American Chemical Society 2012, 134 (36), 14710-14713.

52. Li, F.; Van Heuvelen, K. M.; Meier, K. K.; Münck, E.; Que Jr., L., Sc ${ }^{3+}$-Triggered Oxoiron(IV) Formation from $\mathrm{O}_{2}$ and its NonHeme Iron(II) Precursor via a $\mathrm{Sc}^{3+}-$ Peroxo-Fe ${ }^{3+}$ Intermediate. $J$. Am. Chem. Soc. 2013, 135, 10198-10201.

53. Hong, S.; Pfaff, F. F.; Kwon, E.; Wang, Y.; Seo, M.-S.; Bill, E.; Ray, K.; Nam, W., Spectroscopic Capture and Reactivity of a Low-Spin Cobalt(IV)-Oxo Complex Stabilized by Binding RedoxInactive Metal Ions. Angew. Chem. Int. Ed. 2014, 53, 10403-10407.

54. Holze, P.; Corona, T.; Frank, N.; Braun-Cula, B.; Herwig, C.; Company, A.; Limberg, C., Activation of Dioxygen at a Lewis Acidic Nickel(II) Complex: Characterization of a Metastable Organoperoxide Complex. Angew. Chem. Int. Ed. 2017, 56, 23072311

55. Kal, S.; Draksharapu, A.; Que Jr., L., Sc ${ }^{3+}$ (or $\mathrm{HClO}_{4}$ ) Activation of a Nonheme Fe $\mathrm{F}^{\mathrm{II}}-\mathrm{OOH}$ Intermediate for the Rapid Hydroxylation of Cyclohexane and Benzene. J. Am. Chem. Soc. 2018, 140, 5798-5804.

56. te Velde, G.; Bickelhaupt, F. M.; Baerends, E. J.; Fonseca Guerra, C.; van Gisbergen, S. J. A.; Snijders, J. G.; Ziegler, T., Chemistry with ADF. J. Comput. Chem. 2001, 22 (9), 931-967.

57. Pye, C. C.; Ziegler, T., An implementation of the conductor-like screening model of solvation within the Amsterdam density functional package. Theor. Chem. Acc. 1999, 101 (6), 396408.

58. Swart, M.; Bickelhaupt, F. M., QUILD: QUantum-regions Interconnected by Local Descriptions. J. Comput. Chem. 2008, 29 (5), 724-734

59. Frisch, M. J.; Trucks, G. W.; Schlegel, H. B.; Scuseria, G. E.; Robb, M. A.; Cheeseman, J. R.; Scalmani, G.; Barone, V.; Petersson, G. A.; Nakatsuji, H.; Li, X.; Caricato, M.; Marenich, A. V.; Bloino, J.; Janesko, B. G.; Gomperts, R.; Mennucci, B.; Hratchian, H. P.; Ortiz, J. V.; Izmaylov, A. F.; Sonnenberg, J. L.; Williams; Ding, F.; Lipparini, F.; Egidi, F.; Goings, J.; Peng, B.; Petrone, A.; Henderson, T.; Ranasinghe, D.; Zakrzewski, V. G.; Gao, J.; Rega, N.; Zheng, G.; Liang, W.; Hada, M.; Ehara, M.; Toyota, K.; Fukuda, R.; Hasegawa, J.; Ishida, M.; Nakajima, T.; Honda, Y.; 
Kitao, O.; Nakai, H.; Vreven, T.; Throssell, K.; Montgomery Jr., J. A.; Peralta, J. E.; Ogliaro, F.; Bearpark, M. J.; Heyd, J. J.; Brothers, E. N.; Kudin, K. N.; Staroverov, V. N.; Keith, T. A.; Kobayashi, R.; Normand, J.; Raghavachari, K.; Rendell, A. P.; Burant, J. C.; Iyengar, S. S.; Tomasi, J.; Cossi, M.; Millam, J. M.; Klene, M.; Adamo, C.; Cammi, R.; Ochterski, J. W.; Martin, R. L.; Morokuma, K.; Farkas, O.; Foresman, J. B.; Fox, D. J. Gaussian 16, Wallingford, CT, 2016.

60. Van Lenthe, E.; Baerends, E. J., Optimized Slater-type basis sets for the elements 1-118. J. Comput. Chem. 2003, 24 (9), 1142-1156.

61. Chong, D. P.; Van Lenthe, E.; Van Gisbergen, S.; Baerends, E. J., Even-tempered slater-type orbitals revisited: From hydrogen to krypton. J. Comput. Chem. 2004, 25 (8), 1030-1036.

62. Marcel Swart, Matthias Bickelhaupt, Optimization of strong and weak coordinates, International Journal of Quantum Chemistry (2006) 106(12), 2536-2544. Int. J. Quantum Chem. 2007, 107 (4), 1027-1027.

63. Vosko, S. H.; Wilk, L.; Nusair, M., Accurate spindependent electron liquid correlation energies for local spin density calculations: a critical analysis. Can. J. Phys. 1980, 58 (8), 12001211.

64. Becke, A. D., Density-functional exchange-energy approximation with correct asymptotic behavior. Phys. Rev. A 1988, 38 (6), 3098-3100.

65. Perdew, J. P., Erratum: Density-functional approximation for the correlation energy of the inhomogeneous electron gas. Phys. Rev. B 1986, 34 (10), 7406-7406.

66. Stephens, P. J.; Devlin, F. J.; Chabalowski, C. F.; Frisch, M. J., Ab Initio Calculation of Vibrational Absorption and Circular Dichroism Spectra Using Density Functional Force Fields. The Journal of Physical Chemistry 1994, 98 (45), 11623-11627.

67. Klamt, A.; Schuurmann, G., COSMO: a new approach to dielectric screening in solvents with explicit expressions for the screening energy and its gradient. Journal of the Chemical Society, Perkin Transactions 2 1993, (5), 799-805.

68. Klamt, A., Conductor-like Screening Model for Real Solvents: A New Approach to the Quantitative Calculation of Solvation Phenomena. The Journal of Physical Chemistry 1995, 99 (7), 2224-2235

69. van Lenthe, E.; Ehlers, A.; Baerends, E.-J., Geometry optimizations in the zero order regular approximation for relativistic effects. The Journal of Chemical Physics 1999, 110 (18), 8943-8953.

70. van Lenthe, E.; Baerends, E. J.; Snijders, J. G., Relativistic total energy using regular approximations. The Journal of Chemical Physics 1994, 101 (11), 9783-9792.

71. Dirac, P. A. M., Note on Exchange Phenomena in the Thomas Atom. Mathematical Proceedings of the Cambridge Philosophical Society 2008, 26 (3), 376-385.

72. Slater, J. C., A Simplification of the Hartree-Fock Method. Phys. Rev. 1951, 81 (3), 385-390.

73. Swart, M.; Ehlers, A. W.; Lammertsma, K., Performance of the OPBE exchange-correlation functional. Molec. Phys. 2004, 102 (23-24), 2467-2474.

74. Franchini, M.; Philipsen, P. H. T.; Visscher, L., The Becke Fuzzy Cells Integration Scheme in the Amsterdam Density Functional Program Suite. J. Comput. Chem. 2013, 34 (21), 18191827.

75. Becke, A. D., A multicenter numerical integration scheme for polyatomic molecules. The Journal of Chemical Physics 1988, 88 (4), 2547-2553.

76. Grimme, S.; Antony, J.; Ehrlich, S.; Krieg, H., A consistent and accurate $\mathrm{ab}$ initio parametrization of density functional dispersion correction (DFT-D) for the 94 elements H-Pu. The Journal of Chemical Physics 2010, 132 (15), 154104.

77. Hay, P. J., Gaussian basis sets for molecular calculations. The representation of $3 \mathrm{~d}$ orbitals in transition-metal atoms. The Journal of Chemical Physics 1977, 66 (10), 4377-4384.

78. Wachters, A. J. H., Gaussian Basis Set for Molecular Wavefunctions Containing Third-Row Atoms. The Journal of Chemical Physics 1970, 52 (3), 1033-1036.
79. Binning, R. C.; Curtiss, L. A., Compact contracted basis sets for third-row atoms: Ga-Kr. J. Comput. Chem. 1990, 11 (10), 1206-1216.

80. Kendall, A. J.; Zakharov, L. N.; Gilbertson, J. D., Synthesis and Stabilization of a Monomeric Iron(II) Hydroxo Complex via Intramolecular Hydrogen Bonding in the Secondary Coordination Sphere. Inorg. Chem. 2010, 49 (19), 8656-8658.

81. MacBeth, C. E.; Golombek, A. P.; Young, V. G.; Yang, C.; Kuczera, K.; Hendrich, M. P.; Borovik, A. S., O2 Activation by Nonheme Iron Complexes: A Monomeric Fe(III)-Oxo Complex Derived From O2. Science 2000, 289 (5481), 938-941.

82. MacBeth, C. E.; Gupta, R.; Mitchell-Koch, K. R.; Young, V. G.; Lushington, G. H.; Thompson, W. H.; Hendrich, M. P.; Borovik, A. S., Utilization of Hydrogen Bonds To Stabilize $\mathrm{M}-\mathrm{O}(\mathrm{H})$ Units: Synthesis and Properties of Monomeric Iron and Manganese Complexes with Terminal Oxo and Hydroxo Ligands. J. Am. Chem. Soc. 2004, 126 (8), 2556-2567.

83. de Visser, S. P.; Rohde, J.-U.; Lee, Y.-M.; Cho, J.; Nam, $\mathrm{W}$., Intrinsic properties and reactivities of mononuclear nonheme iron-oxygen complexes bearing the tetramethylcyclam ligand. Coord. Chem. Rev. 2013, 257 (2), 381-393.

84. Hersleth, H.-P.; Ryde, U.; Rydberg, P.; Görbitz, C. H.; Andersson, K. K., Structures of the high-valent metal-ion haemoxygen intermediates in peroxidases, oxygenases and catalases. $J$. Inorg. Biochem. 2006, 100 (4), 460-476.

85. Cho, J.; Jeon, S.; Wilson, S. A.; Liu, L. V.; Kang, E. A.; Braymer, J. J.; Lim, M. H.; Hedman, B.; Hodgson, K. O.; Valentine, J. S.; Solomon, E. I.; Nam, W., Structure and reactivity of a mononuclear non-haem iron(III)-peroxo complex. Nature 2011, 478 (7370), 502-505.

86. Fukuzumi, S.; Morimoto, Y.; Kotani, H.; Naumov, P.; Lee, Y.-M.; Nam, W., Crystal structure of a metal ion-bound oxoiron(IV) complex and implications for biological electron transfer. Nat Chem 2010, 2 (9), 756-759.

87. Mukherjee, J.; Lucas, R. L.; Zart, M. K.; Powell, D. R.; Day, V. W.; Borovik, A. S., Synthesis, Structure, and Physical Properties for a Series of Monomeric Iron(III) Hydroxo Complexes with Varying Hydrogen-Bond Networks. Inorg. Chem. 2008, 47 (13), 5780-5786.

88. Ogo, S.; Yamahara, R.; Roach, M.; Suenobu, T.; Aki, M.; Ogura, T.; Kitagawa, T.; Masuda, H.; Fukuzumi, S.; Watanabe, Y., Structural and Spectroscopic Features of a cis (Hydroxo)-FeIII(Carboxylato) Configuration as an Active Site Model for Lipoxygenases. Inorg. Chem. 2002, 41 (21), 5513-5520.

89. Ogo, S.; Wada, S.; Y., W.; Iwase, M.; Wada, A.; Harata, M.; Jitsukawa, K.; Masuda, H.; Einaga, H., Synthesis, Structure, and Spectroscopic Properties of [Feiii(tnpa)(OH)(PhCOO)]ClO4: A Model Complex for an Active Form of Soybean Lipoxygenase-1. Angewandte Chemie International Edition 1998, 37, 2102-2104.

90. Cook, S. A.; Ziller, J. W.; Borovik, A. S., Iron(II) Complexes Supported by Sulfonamido Tripodal Ligands: Endogenous versus Exogenous Substrate Oxidation. Inorg. Chem. 2014, 53 (20), 11029-11035.

91. Lacy, D. C.; Gupta, R.; Stone, K. L.; Greaves, J.; Ziller, J. W.; Hendrich, M. P.; Borovik, A. S., Formation, Structure, and EPR Detection of a High Spin FeIV-Oxo Species Derived from Either an FeIII-Oxo or FeIII-OH Complex. J. Am. Chem. Soc. 2010, 132 (35), 12188-12190.

92. Rohde, J.; In, J.; Lim, M.; Brennessel, W.; Bukowski, M.; Stubna, A.; Münck, E.; Nam, W.; Que, L., Crystallographic and spectroscopic characterization of a nonheme Fe(IV)-O complex. Science (New York) 2003, 299 (5609), 1037-9.

93. Ray, K.; England, J.; Fiedler, A. T.; Martinho, M.; Münck, E.; Que, L., An Inverted and More Oxidizing Isomer of $[\mathrm{FeIV}(\mathrm{O})(\mathrm{tmc})(\mathrm{NCCH} 3)] 2+$. Angewandte Chemie International Edition 2008, 47 (42), 8068-8071.

94. Jackson, T. A.; Rohde, J.-U.; Seo, M. S.; Sastri, C. V.; DeHont, R.; Stubna, A.; Ohta, T.; Kitagawa, T.; Münck, E.; Nam, W.; Que, L., Axial Ligand Effects on the Geometric and Electronic Structures of Nonheme Oxoiron(IV) Complexes. J. Am. Chem. Soc. 2008, 130 (37), 12394-12407. 
95. Sastri, C. V.; Park, M. J.; Ohta, T.; Jackson, T. A.; Stubna A.; Seo, M. S.; Lee, J.; Kim, J.; Kitagawa, T.; Münck, E.; Que, L.; Nam, W., Axial Ligand Substituted Nonheme FeIVO Complexes: Observation of Near-UV LMCT Bands and FeO Raman Vibrations. J. Am. Chem. Soc. 2005, 127 (36), 12494-12495.

96. Thibon, A.; England, J.; Martinho, M.; Young, V. G.; Frisch, J. R.; Guillot, R.; Girerd, J.-J.; Münck, E.; Que, L.; Banse, F., Proton- and Reductant-Assisted Dioxygen Activation by a Nonheme Iron(II) Complex to Form an Oxoiron(IV) Intermediate. Angewandte Chemie (International ed. in English) 2008, 47 (37), 7064-7067.

97. Bukowski, M. R.; Koehntop, K. D.; Stubna, A.; Bominaar, E. L.; Halfen, J. A.; Münck, E.; Nam, W.; Que, L., A ThiolateLigated Nonheme Oxoiron(IV) Complex Relevant to Cytochrome P450. Science 2005, 310 (5750), 1000-1002.

98. McDonald, A. R.; Bukowski, M. R.; Farquhar, E. R.; Jackson, T. A.; Koehntop, K. D.; Seo, M. S.; De Hont, R. F.; Stubna, A.; Halfen, J. A.; Münck, E.; Nam, W.; Que, L., Sulfur versus Iron Oxidation in an Iron-Thiolate Model Complex. J. Am. Chem. Soc. 2010, 132 (48), 17118-17129.

99. Klinker, E. J.; Kaizer, J.; Brennessel, W. W.; Woodrum, N. L.; Cramer, C. J.; Que, L., Structures of Nonheme Oxoiron(IV) Complexes from X-ray Crystallography, NMR Spectroscopy, and DFT Calculations. Angewandte Chemie International Edition 2005, 44 (24), 3690-3694.

100. Kaizer, J.; Klinker, E. J.; Oh, N. Y.; Rohde, J.-U.; Song, W. J.; Stubna, A.; Kim, J.; Münck, E.; Nam, W.; Que, L., Nonheme FeIVO Complexes That Can Oxidize the $\mathrm{C}-\mathrm{H}$ Bonds of Cyclohexane at Room Temperature. J. Am. Chem. Soc. 2004, 126 (2), 472-473.

101. England, J.; Guo, Y.; Farquhar, E. R.; Young Jr, V. G.; Münck, E.; Que Jr, L., The Crystal Structure of a High-Spin Oxoiron(IV) Complex and Characterization of Its Self-Decay Pathway. J. Am. Chem. Soc. 2010, 132 (25), 8635-8644.
102. England, J.; Martinho, M.; Farquhar, E. R.; Frisch, J. R.; Bominaar, E. L.; Münck, E.; Que, L., A Synthetic High-Spin Oxoiron(IV) Complex. Generation, Spectroscopic Characterization and Reactivity. Angewandte Chemie (International ed. in English) 2009, 48 (20), 3622-3626.

103. Bigi, J. P.; Harman, W. H.; Lassalle-Kaiser, B.; Robles, D. M.; Stich, T. A.; Yano, J.; Britt, R. D.; Chang, C. J., A High-Spin Iron(IV)-Oxo Complex Supported by a Trigonal Nonheme Pyrrolide Platform. J. Am. Chem. Soc. 2012, 134 (3), 1536-1542.

104. Swart, M.; Groenhof, A. R.; Ehlers, A. W.; Lammertsma, K., Validation of Exchange-Correlation Functionals for Spin States of Iron Complexes. The Journal of Physical Chemistry A 2004, 108 (25), 5479-5483.

105. Stepanovic, S.; Andjelkovic, L.; Zlatar, M.; Andjelkovic, K.; Gruden-Pavlovic, M.; Swart, M., Role of Spin State and Ligand Charge in Coordination Patterns in Complexes of 2,6Diacetylpyridinebis(semioxamazide) with 3d-Block Metal Ions: A Density Functional Theory Study. Inorg. Chem. 2013, 52 (23), 13415-13423.

106. Swart, M., Metal-ligand bonding in metallocenes: differentiation between spin state, electrostatic and covalent bonding. Inorg. Chim. Acta 2007, 360, 179-189.

107. Swart, M., Accurate Spin-State Energies for Iron Complexes. J. Chem. Theory Comp. 2008, 4 (12), 2057-2066.

108. Swart, M.; Ehlers, A. W.; Lammertsma, K., The performance of OPBE. Molec. Phys. 2004, 102, 2467-2474.

109. Zhou, A.; Kleespies, S. T.; Van Heuvelen, K. M.; Que Jr., L., Characterization of a heterobimetallic nonheme $\mathrm{Fe}$ (III)-O-Cr(III) species formed by $\mathrm{O}_{2}$ activation. Chem. Commun. 2015, 51, 1432614329. 